\title{
DO INTRODUCTORY STATISTICS COURSES IN THE UNITED STATES IMPROVE STUDENTS' ATTITUDES?
}

\author{
CANDACE SCHAU \\ CS Consultants, $L L C$ \\ Professor Emerita, University of New Mexico \\ cschau@comcast.net \\ ESMA EMMIOĞLU \\ Gaziosmanpasa University \\ esma.Emmioglu@gmail.com
}

\begin{abstract}
We examined the attitudes of about 2200 students enrolled in 101 sections of post-secondary introductory statistics service courses located across the United States. Using the Survey of Attitudes Toward Statistics-36, we assessed students' attitudes when they entered and left their courses, as well as changes in attitudes across their courses. Results showed that, on average, students entered these courses with neutral (Affect, Difficulty), positive (Cognitive Competence, Value, Interest), and very positive (Effort) attitudes. Their attitudes either stayed about the same (Affect, Cognitive Competence, Difficulty) or decreased (Value, Interest, Effort). These results help us understand the current impact of introductory statistics instruction in U.S. institutions.
\end{abstract}

Keywords: Statistics education research; Statistics attitudes; Attitude changes

\section{INTRODUCTION}

In most disciplines, students' academic attitudes are considered extremely important. A large number of educational and cognitive theories, with a great deal of research corroboration, support the conclusion that students' attitudes toward the discipline are important course outcomes and, in fact, are at least as important as knowledge and skills in the discipline (see, for example, chapters about many of these theories found in Wentzel \& Wigfield, 2009). When applied to statistics education, these theories and findings from other disciplines, including mathematics, suggest that students who leave their statistics courses with negative attitudes are unlikely ever to use what they have learned. That is, they will not intelligently and literately use statistics in their professional and personal lives or in any educational venture. Because most students only take one statistics course, the introductory course is where we, as statistics educators, have the best opportunity to positively impact students' attitudes. Only a few research studies conducted in the United States have examined students' changes in attitudes across these post-secondary courses. The findings from these studies indicate that, on average, students' attitudes often did not change or they became more negative (e.g., Evans, 2007; Schau, 2003b; Sizemore \& Lewandowski, 2009). Most frequently these studies have been done with students enrolled in specific statistics courses taught in one institution. The instructors of these courses often came from a variety of departments (e.g., statistics, psychology, business). It is unclear whether these findings represent trends across the United States or whether they only apply to the students enrolled in these specific courses.

The major goal of this study was to examine students' attitudes in their introductory statistics service courses taught in mathematics or statistics departments across the United States. We examined students' attitudes when they entered and left their courses, as well as the changes in their attitudes across their courses. Specifically, we explored

1. students' attitudes toward statistics at the beginning and end of their introductory statistics courses,

Statistics Education Research Journal, 11(2), 86-94, http://www.stat.auckland.ac.nz/serj

(0) International Association for Statistical Education (IASE/ISI), November, 2012 
2. changes in students' attitudes from the beginning to the end of their courses.

\section{METHOD}

\subsection{DATA COLLECTION INSTRUMENT}

We selected the Survey of Attitudes Toward Statistics-36 (SATS-36; Schau, 2003a) to assess students' attitudes for four reasons. First, it is congruent with Eccles and colleagues' ExpectancyValue Theory (EVT), a theory that has been used extensively in mathematics education to explore achievement-related course outcomes. Second, it has been used widely both within the United States and in other countries. Third, scores from students involved in these studies have generally shown good to excellent psychometric properties (e.g., Bechrakisa, Gialamasb, \& Barkatsas, 2011; Chiesi \& Primi, 2009; Hilton, Schau, \& Olsen, 2004; Tempelaar, Schim van der Loeff, \& Gijselaers, 2007). Fourth, like EVT, it is comprehensive; it assesses multiple components of students' attitudes.

The SATS-36 contains 36 items that assess six statistics attitude components. To view all of the SATS-36 pretest items see the Scoring Guide (www.evaluationandstatistics.com). Definitions of the six components and example pretest items include

- Affect (6 items) - students' positive and negative feelings concerning statistics - "I am scared by statistics."

- Cognitive Competence (6 items) - students' attitudes about their intellectual knowledge and skills when applied to statistics - "I can learn statistics."

- Value (9 items) - students' attitudes about the usefulness, relevance, and worth of statistics in personal and professional life - "I use statistics in my everyday life."

- Difficulty (7 items) - students' attitudes about the difficulty of statistics as a subject - "Most people have to learn a new way of thinking to do statistics."

- Interest (4 items) - students' level of individual interest in statistics - "I am interested in using statistics."

- Effort (4 items) - amount of work the student expends to learn statistics - "I plan to work hard in my statistics course."

Students respond to each of the 36 items comprising the six attitude components on a 7-point Likert scale: 1 = "Strongly Disagree", 4 = "Neither Disagree nor Agree" (neutral or no attitude), and 7 = "Strongly Agree." Some items are positively worded while some are negatively worded. Responses to the negatively-worded items are reversed before scoring. A student who gives a higher numerical response to any item has a more positive attitude than one who gives a lower response. A student's score for each attitude component is calculated as the mean response to all items that assess that component. Because mean responses vary across items, a student must complete all items in a component to receive a component score. The meaning of positive attitudes is clear for all components, except for Difficulty. Higher scores on the Difficulty component indicate that students believe that statistics is easier whereas lower scores mean that they think it is harder.

\subsection{DATA SOURCES AND PROCEDURES}

Students' responses to the SATS-36 items were obtained from two sources: the SATS Project and donated data. The responses from both sources were combined for this paper.

For the SATS Project, Marjorie Bond, from Monmouth College, and Candace Schau developed a website to collect SATS data from students and information from their instructors. Any instructor teaching an undergraduate statistics course in the United States could participate at no cost. Interested instructors obtained approval from their institution's human subject ethics review boards. Some instructors offered their students a minimal amount of extra credit for participating. Students could opt out of participation without penalty. At the conclusion of their terms, participating instructors received a data file containing their students' responses and attitude component scores; these data were anonymous. The Project was approved each year by the Monmouth College Human Subject Review Board. Data were collected during the academic years beginning in the fall term of 2007 and ending with the spring term of 2010. In addition, some researchers, with approval of their human subject 
ethics review boards, have shared their post-secondary students' SATS responses with researchers. Shared student responses again were anonymous. These data were collected during the academic years beginning in the fall term of 2006 and ending with the spring term of 2008.

The two data sources contained responses from students who were enrolled in many different kinds of statistics courses taught in various academic departments in diverse U.S. institutions. Our interest in this article is in the attitudes of those students with a variety of majors who were enrolled in introductory statistics courses either with no mathematics prerequisite or with an algebra prerequisite that were taught in mathematics or statistics departments; these types of courses often are called service courses. We selected this sample for three reasons. First, introductory statistics courses are the focus of many of the research studies in U.S. statistics education. Second, we selected introductory service courses taught in mathematics and statistics departments because we do not know whether students in other courses will show the same results. Third, we eliminated courses taught in other countries as we do not know whether the U.S. results will replicate in other nations.

The data came from institutions that varied from small private and public four-year colleges to large research institutions that award advanced degrees. This variability allowed a wide representation of students enrolled in introductory statistics service courses, as well as of the courses themselves. Regardless of the source, students responded to the SATS-36 items on the web during or outside of class, within a maximum time period of two weeks at the beginning and at the end of the course.

\subsection{ANALYSIS APPROACH}

To interpret the importance of findings, rather than only their statistical significance, authors usually recommend that researchers select values based on reasonable assumptions about the size of findings needed for importance in the field under study, given the measure being used (e.g., Cohen, 1988). Using this approach, we considered differences of about $1 / 2$ point or more as important. That value represents a change of about $8 \%$ of the possible range in the Likert scale for each item. As examples, we describe how students could change their scores by $1 / 2$ point on the Interest component, one of the components with 4 items (the fewest number of items in a component), and on the Value component (the component with 9 items, the greatest number of items). For Interest, students' scores would change by $1 / 2$ point if they changed their Likert scale responses by 1 point on two items (half of the items in the component) or by 2 points on one item. Students could change their scores by slightly over $1 / 2$ point on the Value component by changing their scale responses by 1 point on 5 items (about half of the items) or in several other ways. We believe that this degree of change is important.

Many statistics education researchers studying changes in any kind of pretest-posttest scores analyze results by pooling across students from many courses. However, sections are composed of students and their instructors (sometimes course instructors, sometimes course and lab or tutorial instructors), instructional approaches, content, and the physical locations in which the sections meet. Together, these create the introductory statistics course experience for both students and instructors. To capture this experience, we used sections as our unit of analysis. In addition, we also calculated means and standard deviations for all students combined into one group so researchers and instructors can easily compare our results with their own (and with the results from others). Internal consistencies were calculated in the usual manner using student responses to items within each component.

To examine attitude changes, we utilized responses from students who completed both the pretest and the posttest, the approach taken by most researchers and instructors who have collected pretestposttest data. A total of 101 sections provided matched pretest-posttest component scores for their individual students. Approximately 2200 students provided data from these sections. Number of student participants varied across sections. About $92 \%$ (93) of the sections contained at least 10 but no more than 50 students. About 6\% (6 sections) included fewer than 10 students, whereas $2 \%$ (2 sections) included over 50 students. In our data set, institutions offering large courses generally split their students into smaller groups for labs or tutorials so we had few large sections. Of these 101 sections, $52 \%$ (53 sections) came from four-year institutions whereas $48 \%$ (48 sections) came from advanced degree-granting institutions. The instructors from all sections reported using face-to-face teaching, although some also included on-line instruction and/or homework. We examined potential relationships among number of participants who took the SATS in the sections and the corresponding mean section component scores for pretest, posttest, and change (posttest - pretest) for each of the six 
components. The resulting 18 correlation coefficients were small (range from -.12 to .07). We also examined possible section mean differences by institution type (four-year and advanced degreegranting) for each of the 18 mean section attitude scores. All of the mean differences by institution type were less than $1 / 2$ point. Thus, we included all sections in our analyses.

\section{RESULTS}

\subsection{INTERNAL CONSISTENCY}

Before interpreting scores from any sample, we need to be certain that they exhibit at least adequate internal consistency, frequently evaluated using Cronbach's coefficient alpha. Like effect sizes, authors often recommend selecting an approximate lower limit for alpha that reflects the degree of error that researchers find acceptable in their studies. We selected 0.70 , an alpha value often used in other research (Pedhazur \& Schmelkin, 1991). The pretest and posttest alpha values showed that all six components exhibited good to excellent internal consistencies (Table 1).

Table 1. Cronbach's alpha values for pretest and posttest scores by attitude component

\begin{tabular}{lcc}
\hline & \multicolumn{2}{c}{ Time of Administration } \\
\cline { 2 - 3 } Attitude Component & Pretest & Posttest \\
\hline Affect & .81 & .85 \\
Cognitive Competence & .84 & .86 \\
Value & .87 & .90 \\
Difficulty & .76 & .79 \\
Interest & .89 & .91 \\
Effort & .81 & .77 \\
\hline
\end{tabular}

\subsection{PRETEST ATTITUDES}

Mean pretest section scores, as well as the variability in these mean scores, differed across sections as well as across attitude components. Figure 1 presents box plots of the section mean pretest scores for each attitude component.

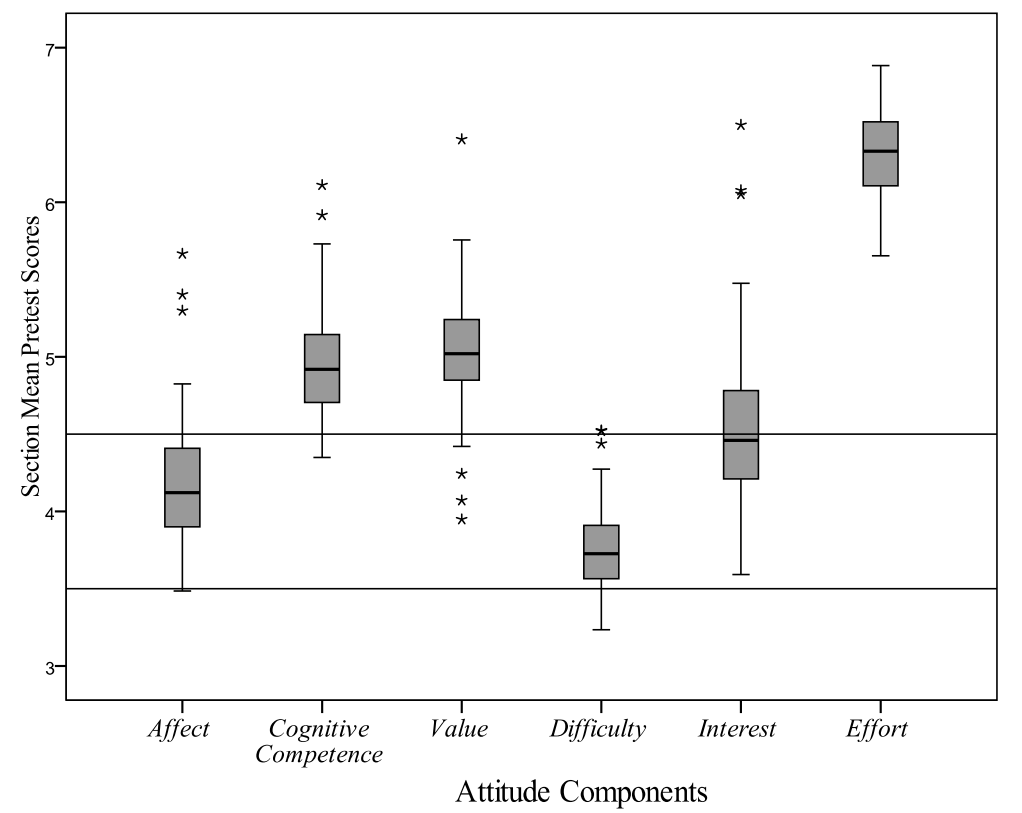

Figure 1. Box plots of section mean pretest scores by attitude component 


\subsection{POSTTEST ATTITUDES}

Like the pretest, mean section posttest scores and their variabilities differed by section and by component. Figure 2 presents box plots of the section mean posttest scores for each attitude component.

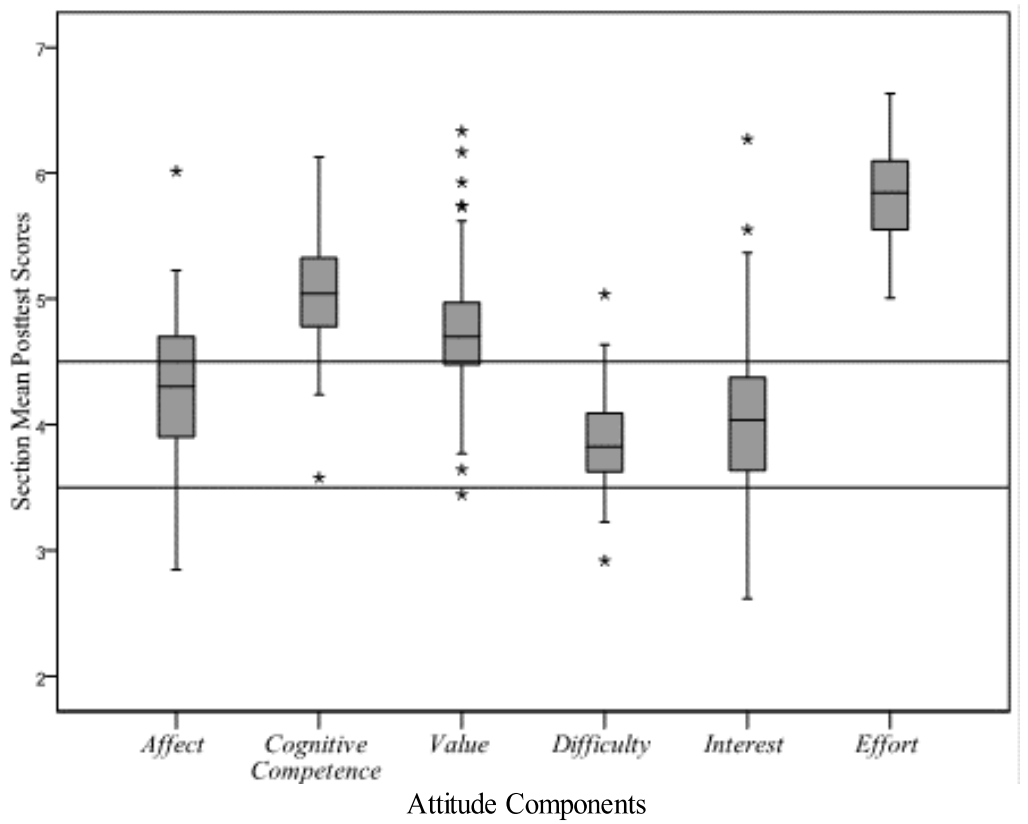

Figure 2. Box plots of section mean posttest scores by attitude component

The average section scores from the three attitude components of Affect, Difficulty, and Interest were essentially neutral; their medians were within $1 / 2$ point of 4 . Most of the section means fell in the neutral range for Difficulty. Many of the section means for Affect and Interest also fell within the neutral range; however, some sections exhibited positive average attitudes and some negative attitudes. The median section mean score for Value was almost $3 / 4$ point above neutral, an important difference, with about $3 / 4$ of the sections in the positive range and the remainder in the neutral range. The section median for Cognitive Competence was about one point above neutral, with the great majority of section means in the positive range. The mean section score for Effort was almost two points above neutral, with all section means in the positive range.

Mean scores were most variable across sections for Interest and Affect, each with an IQR greater than or equal to $3 / 4$ point. The remaining mean posttest scores were about equally variable with IQRs of about $1 / 2$ point. Posttest variability of mean scores was greater than that for pretest variability for every component.

\subsection{ATTITUDE CHANGES}

As expected from the pretest and posttest results, the means and standard deviations of the attitude change scores (posttest - pretest) varied across sections and attitude components. The box plots in Figure 3 display the section mean change scores by component.

Affect, Cognitive Competence, Value, and Difficulty section mean scores stayed about the same from pretest to posttest. Most of the Difficulty section means did not change (within the range from $-1 / 2$ to $+1 / 2$ point). A majority of section means for Affect and Cognitive Competence also fell within that range, but some showed improved or worsened attitudes. Unfortunately, for Value, about $25 \%$ of the section means worsened while the remainder showed no change. The median section mean change scores for Interest and Effort decreased by about $1 / 2$ point, important decreases. Attitudes in about $50 \%$ of the sections got worse and about $50 \%$ showed no change. 


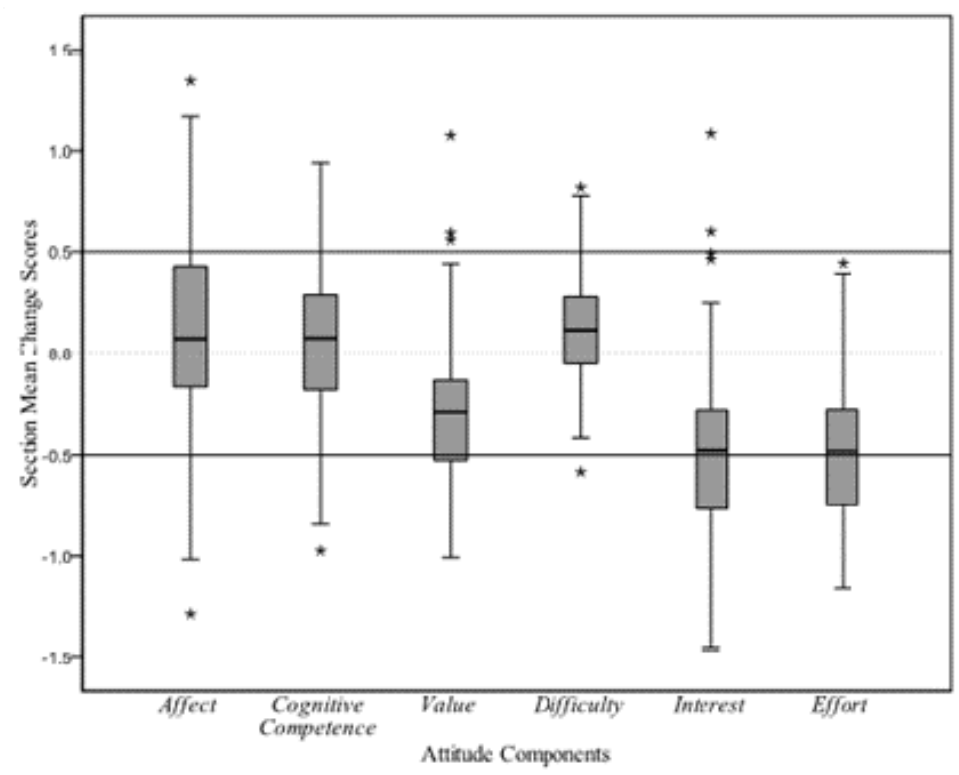

Figure 3. Box plots of section mean change scores by attitude component

In terms of the variability of section mean change scores across attitude components, Affect exhibited the largest IQR of almost $2 / 3$ point. Value and Difficulty exhibited the smallest IQR values of almost $4 / 10$ point.

\subsection{STUDENT-BASED DESCRIPTIVE STATISTICS}

Table 2 gives the sample sizes, means, and standard deviations for pretest, posttest and change scores with students as the unit of analysis. The student-based means are close to the section-based medians displayed in Figures 1-3 and described in the associated text. This similarity then yields the same patterns across components and time of administration. Although the student-based standard deviations are much larger, of course, than the IQR values for mean scores across sections, again the patterns of most and least variable components are similar.

Table 2. Student-based means and standard deviations for pretest, posttest, and change scores by attitude component

\begin{tabular}{lccccccc}
\hline & & \multicolumn{3}{c}{ Pretest } & \multicolumn{2}{c}{ Posttest } & \multicolumn{2}{c}{ Change } \\
\cline { 2 - 8 } Affect & $n$ & $M$ & $S D$ & $M$ & $S D$ & $M$ & $S D$ \\
\cline { 2 - 7 } Cognitive Competence & 2209 & 4.16 & 1.12 & 4.30 & 1.32 & .13 & 1.23 \\
Value & 2192 & 4.94 & 1.04 & 5.03 & 1.16 & .10 & 1.06 \\
Difficulty & 2186 & 5.04 & .99 & 4.72 & 1.12 & -.32 & .96 \\
Interest & 2204 & 3.75 & .81 & 3.90 & .96 & .15 & .84 \\
Effort & 2219 & 4.51 & 1.27 & 4.00 & 1.44 & -.50 & 1.25 \\
& 2246 & 6.32 & .90 & 5.84 & 1.09 & -.48 & 1.14 \\
\hline
\end{tabular}

\section{DISCUSSION}

Mean attitudes differed by section, attitude component, and time of administration of the SATS36. Regardless of whether section-based or student-based mean scores were examined, students neither liked nor disliked statistics at the beginning of their introductory courses. On average, they believed that statistics wasn't going to be easy or difficult. They valued statistics somewhat. They tended to believe that they would be able to learn statistics. They were slightly more interested than 
disinterested in statistics, although about half of the sections were neutral in their interest. They reported that they expected to expend a great deal of Effort to learn statistics, probably too much to be reasonable.

Applying theories and research findings from other academic disciplines to statistics education, students will not employ statistics in life, in their work, or in other courses unless they believe it is useful. They will use statistics only if they believe that they can do statistics. People will choose to engage in statistical tasks and courses that they find interesting and that they like. In addition, students need to believe that the amount of work they expend to learn and do statistics is reasonable. We want students to at least maintain, or preferably to improve, their attitudes in these components. However, if they believe that statistics is too difficult or too easy, it is likely that they will not even try to understand and use statistics (but for different reasons). Did we find these patterns?

At the end of their introductory courses, in general and regardless of whether section-based or student-based mean scores were examined, students still neither liked nor disliked statistics. On average, they believed in their knowledge and skills to about the same extent that they had at the beginning of their courses. They still believed that statistics wasn't easy or difficult. Unfortunately, in general, they now clearly were neutral in their interest in statistics, although some sections that had expressed neutral attitudes now were disinterested; in general, the attitudes in about half of the sections dropped by at least $1 / 2$ point from pretest to posttest. They still valued statistics, on average, but almost $25 \%$ of the sections moved from positive to neutral attitudes. They still reported expending a great deal of Effort, but less than they had planned to spend (or thought that they would need to spend) at the beginning of their courses.

At pretest, on average, Difficulty attitudes were neutral and Effort attitudes were very high. So no change in Difficulty attitudes and a decrease in Effort attitudes may be acceptable. However we want improvement in the other four components. Instead, on average, we found no changes in Affect and Cognitive Competence and a decrease in Interest attitudes; about $25 \%$ of the sections moved from the positive into the neutral range for Value. What can we do to improve students' attitudes?

We have little research evidence regarding the types of interventions that will improve students' attitudes and what factors affect the impact of these interventions. When improvements in attitudes have been found, they often are associated with extensive instructional changes. For example, Carlson and Winquist (2011) used a workbook curriculum approach. Students read content both before and during class and worked on problem-solving activities during class. These researchers found positive and important mean increases in their students' Affect and Cognitive Competence scores and decreases in Effort scores. At the beginning of their course, students reported that statistics was somewhat difficult; on the posttest, their mean Difficulty score moved to neutral. Posner (2011) evaluated his PARLO System (Proficiency-based Assessment and Reassessment of Learning Outcomes) which included setting learning objectives, assessing students' performance using proficiency-based scoring, and allowing students who did not achieve mastery on their first attempt to resubmit that homework assignment a second time. He reported better mean attitudes for the PARLO group than for the Control group on all six SATS attitude components. Harlow, Burkholder, and Morrow (2002) used an instructional approach that they called "learning enhancement activities" (p. 414); these activities included peer mentoring, student feedback on class clarity, small group problem-solving and hands-on applied projects. Using measures other than the SATS, they reported decreased quantitative anxiety and increased quantitative self-efficacy.

The instructors in our study were interested in their students' attitudes, at least enough to volunteer to participate in the data collection and to measure their students' attitudes at the beginning and at the end of their courses. We believe that they wanted to be good teachers and wanted their students to have positive experiences in their statistics courses. As these instructors, on average, did not obtain the desired attitude changes in their students, it is our contention that other instructors who do not consider attitudes to be of importance are unlikely to do so.

This project is a first step in examining attitudes in U.S. introductory statistics courses. Researchers can build on our work in at least eight ways. First, to expand these findings, researchers could use a sampling scheme to recruit U.S. instructors and students. This approach would hopefully result in an even wider variety of types of students, courses, instructors, and institutions (including community colleges, an important type of post-secondary institution that is not represented in our data set). Similarly, a study such as ours is needed in other countries. 
Second, we need complete student, course, and instructor information to accompany the attitude data. This information will allow us to explore the correlates of stability and change in statistics attitudes. Used in conjunction with theoretical models and findings from other disciplines, this information should suggest instructional approaches to implement and evaluate for their efficacy in improving student attitudes, at the individual and section levels. At least two measures exist for this purpose: the Statistics Teaching Inventory (Zieffler, Park, Garfield, delMas, \& Bjornsdottir, 2012) and the SATS Project Instructor and Course surveys developed for the SATS Project.

Third, students' attitudes showed differences in variability. These differences occurred between and within sections, as well as across attitude components and time of administration. It may be easier for students' attitudes to change (both positively and negatively) on some components than on others. Perhaps these differences in variability are related to ease of attitude change, an area for future research.

Fourth, pretest Effort scores consistently fall near the top of the seven-point Likert scale. This location means that most students' and sections' scores on this component couldn't become more positive at posttest. The best statistical methods to deal with this problem in survey scales like Effort are not yet clear.

Fifth, as mentioned above, we don't want students to believe that statistics is either too easy or too hard. That is, Difficulty scores may be related to other components, factors, and outcomes in a nonlinear fashion.

Sixth, we want representative samples of instructors and all of their students to participate. Thus, researchers need to make a concentrated and sustained effort to recruit and retain instructors and students alike in this type of research. We want to understand the attitudes of all students (and instructors); that understanding requires high participation rates.

Seventh, because we can never recruit and retain everyone, researchers and instructors need to examine the attitudes of those students who take only the pretest or only the posttest. Students who complete only the pretest often have dropped their statistics course, either formally or informally by not attending, or have instructors who did not give them adequate time at the end of the term to complete the posttest. Students who complete only the posttest often added the course too late to participate in the pretest. Participation itself may be a proxy measure for attitudes toward statistics, the course, and/or the instructor.

Eighth, researchers need to carefully consider the best possible time to measure students' attitudes. Of course, the optimal time to assess attitudes is before students begin their courses (pretest) and after they have completed them but before they have received their course grades (posttest). This timing, however, may not be possible to achieve because of student access and motivation issues.

This study helps us begin to understand the current impact of introductory statistics instruction in U.S. post-secondary institutions. Our results showed that, in the United States, these courses are not "enough" to improve (or, for some attitude components, to even maintain) students' attitudes toward statistics. Why did some sections' attitudes change while others did not? If students' attitudes are important to us as statistics educators, we need to identify student, instructor, instructional, and course characteristics that are related to desired attitude outcomes. We then need to design our courses to build on these characteristics and evaluate their effects on course outcomes. We need to evaluate all of our instruction for its impact on students' attitudes toward statistics.

\section{ACKNOWLEDGEMENTS}

The research reported in this paper was supported partially by the Consortium for the Advancement of Undergraduate Statistics Education (CAUSE) through NSF Award \#0618790. We are grateful to the organizers of the USCOTS 2009 (United States Conference On Teaching Statistics) for starting our Attitudes Research Cluster. We also want to thank the many instructors and students who contributed data to this project. 


\section{REFERENCES}

Bechrakisa, T., Gialamasb, V., \& Barkatsas, A. N. (2011). Survey of Attitudes Toward Statistics (SATS): An investigation of its construct validity and its factor structure invariance by gender. International Journal of Theoretical Educational Practice, 1(1), 1-15.

Carlson, K. A., \& Winquist, J. R. (2011). Evaluating an active learning approach to teaching introductory statistics: A classroom workbook approach. Journal of Statistics Education, 19(1). [Online: http://www.amstat.org/publications/jse/v19n1/carlson.pdf]

Chiesi, F., \& Primi, C. (2009). Assessing statistics attitudes among college students: Psychometric properties of the Italian version of the Survey of Attitudes Toward Statistics (SATS). Learning and Individual Differences, 19(2), 309-313.

Cohen, J. (1988). Statistical power analysis for the behavioral sciences (2nd ed.). Hillsdale, NJ: Lawrence Erlbaum.

Evans, B. (2007). Student attitudes, conceptions, and achievement in introductory undergraduate college statistics. The Mathematics Educator, 17(2), 24-30.

[Online: http://math.coe.uga.edu/tme/issues/v17n2/v17n2 Evans.pdf]

Harlow, L. L., Burkholder, G. J., \& Morrow, J. A. (2002). Evaluating attitudes, skill, and performance in a learning-enhanced quantitative methods course: A structural modeling approach. Structural Equation Modeling, 9(3), 413-430.

Hilton, S. C., Schau, C., \& Olsen, J. A. (2004). Survey of Attitudes Toward Statistics: Factor structure invariance by gender and by administration time. Structural Equation Modeling, 11(1), 92-109.

Pedhazur, E. J., \& Schmelkin, L. P. (1991). Measurement, design, and analysis: An integrated approach. Hillsdale, NJ: Erlbaum.

Posner, M. A. (2011). The impact of a proficiency-based assessment and reassessment of learning outcomes system on student achievement and attitudes. Statistics Education Research Journal, 10(1), 3-14.

[Online: http://www.stat.auckland.ac.nz/ iase/serj/SERJ10\%281\%29 Posner.pdf]

Schau, C. (2003a). Survey of Attitudes Toward Statistics (SATS-36).

[Online: http://evaluationandstatistics.com/]

Schau, C. (2003b, August). Students' attitudes: The "other" important outcome in statistics education. Paper presented at the Joint Statistical Meetings, San Francisco, CA. [Online: http://evaluationandstatistics.com/JSM2003.pdf]

Sizemore, O. J., \& Lewandowski, G. W. (2009). Learning might not equal liking: Research methods course changes knowledge but not attitudes. Teaching of Psychology, 36(2), 90-95.

Tempelaar, D. T., Schim van der Loeff, S., \& Gijselaers, W. H. (2007). A structural equation model analyzing the relationship of students' attitudes toward statistics, prior reasoning abilities, and course performance. Statistics Education Research Journal, 6(2), 78-102.

[Online: http://www.stat.auckland.ac.nz/ iase/serj/SERJ6\%282\%29 Tempelaar.pdf]

Wentzel, K. R., \& Wigfield, A. (2009). Handbook of motivation at school. New York: Routledge.

Zieffler, A., Park, J., Garfield, J., delMas, R., \& Bjornsdottir, A. (2012). The Statistics Teaching Inventory: A survey on statistics teachers' classroom practices and beliefs. Journal of Statistics Education, 20(1).

[Online: www.amstat.org/publications/jse/v20n1/zieffler.pdf]

CANDACE SCHAU

CS Consultants, LLC

12812 Hugh Graham Road NE

Albuquerque, New Mexico, 87111 